\title{
Evaluation of Allergic Rhinitis and Asthma Control in a Portuguese Community Pharmacy Setting
}

\author{
Olga Lourenço, PhD; Sofia Calado, MSc; Ana Sá-Sousa, MSc; and João Fonseca, PhD
}

\begin{abstract}
BACKGROUND: Allergic rhinitis and asthma (ARA) are frequent respiratory diseases that often coexist, causing a high social and economic impact. It is important to maintain ARA disease control to reduce the disease burden.

OBJECTIVE: To assess control in patients with 1 or both pathologies through the application of validated questionnaires at community pharmacies.

METHODS: A cross-sectional study was conducted in the pharmacies of the Portuguese county of Covilhã (located in the central region of Portugal with about 53,000 inhabitants). Subjects aged between 18 and 70 years who presented a prescription for an asthma and/or allergic rhinitis medication were invited to participate in the study by responding to a questionnaire that included the Control of Allergic Rhinitis and Asthma Test (CARAT). The CARAT is a validated tool to simultaneously assess the control of ARA with scores that range from 0 to 30 points, 0 meaning the worst and 30 meaning the best possible control of disease.
\end{abstract}

RESULTS: Of the 224 participants, $58 \%$ were female and the median age was 48.5 years. The median CARAT score was 19 (mean $=17.8 \pm 5136.4$ ), and $87 \%$ of participants had a score $<25$, indicating noncontrolled disease. Female participants, the elderly, and those with less school education responded with scores that demonstrated significantly less disease control.

CONCLUSIONS: Using a simple self-assessment questionnaire, such as the CARAT, pharmacists can help identify patients with uncontrolled ARA disease, which is an important first step to change patients' knowledge about their disease, with an ultimate goal of improving ARA outcomes.

J Manag Care Pharm. 2014;20(5):513-22

Copyright $\odot 2014$, Academy of Managed Care Pharmacy. All rights reserved.

\section{What is already known about this subject}

- Allergic rhinitis and asthma (ARA) are common respiratory diseases that are strongly linked. More than $80 \%$ of asthma patients have allergic rhinitis (AR), and up to $40 \%$ of patients with AR have asthma.

- Epidemiological, clinical, and pathological studies suggest that the upper and lower airways provide for "a continuum of a disease."

- According to the guidelines of the Global Initiative for Asthma, the goal of asthma therapy is to achieve overall control for extended periods.

- When asthma is under control, there should be no more than occasional symptoms, and exacerbations should be rare. Effective treatment exists, and ARA education and pharmaceutical interventions can improve control of both respiratory diseases.
- Several standardized measures to assess the clinical control of asthma have been developed, and methods to assess control of AR in the community are now being introduced. The Control of Allergic Rhinitis and Asthma Test (CARAT) is a tool that was developed and validated to simultaneously assess the control of both diseases of the upper and lower airways.

\section{What this study adds}

- AR is a disease with high prevalence, often underdiagnosed and undertreated, and few studies have been conducted to analyze its control in a community setting. This study is the first conducted in a community pharmacy setting that assessed AR and asthma control simultaneously.

- Results show that AR control is as low as control for asthma. Almost half of the study cohort was only diagnosed with AR, but in this group, the control of AR was only slightly better than the control in patients with asthma and AR.

- In patients diagnosed only with AR, about 50\% had a score corresponding to poor asthma control, which may mean a lack of an asthma diagnosis in some cases.

- The sharp contrast between perception of disease control and actual control suggests that administering the CARAT while the patient is at the pharmacy may be an opportunity to increase patient awareness of poor control.

- The community pharmacist plays an important role for ARA control, providing information about medications, including frequency of administration, minimalization of side effects, and correct use of the inhaler devices.

A sthma is a condition of chronic airway inflammation, associated with hyperreactivity of the airways, leading to recurrent episodes of breathlessness, wheezing, chest tightness, and coughing, particularly at night or in the early morning. ${ }^{1}$ It is a chronic disease that is prevalent worldwide and affects approximately 300 million people of all ages, including 17.7 million American adults. ${ }^{2,3}$ Allergic rhinitis (AR) is the most common form of noninfectious rhinitis and is one of the most prevalent diseases of the airways. ${ }^{4,5}$ It is characterized by rhinorrhea, sneezing, nasal pruritus, and/or nasal obstruction. ${ }^{6,7}$ It is frequently undertreated and underdiagnosed and consequently uncontrolled. ${ }^{4}$ Patients suffering from AR often adapt to symptoms or self-medicate to relieve symptoms. ${ }^{6,8}$ 


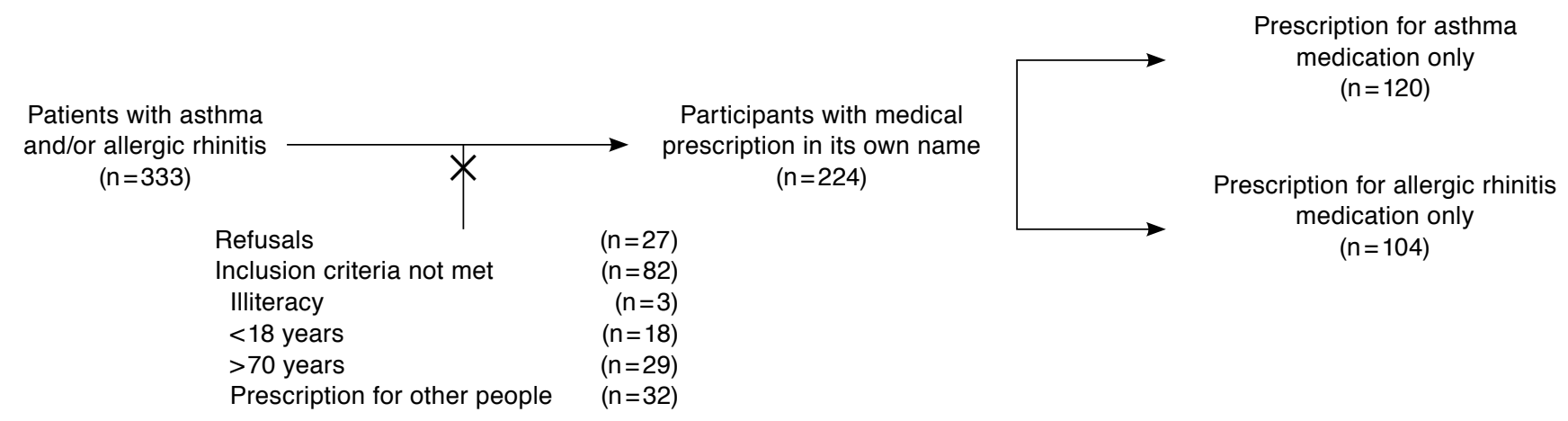

after excluding refusals and cases not meeting inclusion criteria, this study had 224 participants (asthma and rhinitis subgroup, $n=120$; allergic rhinitis only subgroup, $n=104$ ).

In Western Europe, including Portugal, the overall prevalence of clinically confirmed AR is about $23 \%-26 \% .{ }^{6}$ In the United States, an estimated 50 million Americans, about $16 \%$ of the population, are thought to be affected by AR. ${ }^{9}$

Data suggest that the upper and lower airways can be thought of as "a continuum of a disease." ${ }^{10}$ Epidemiological, clinical, and pathological studies establish a strong link between asthma and allergic rhinitis, and they often occur together, as more than $80 \%$ of asthma patients have AR, and up to $40 \%$ of patients with AR have asthma. ${ }^{5}$ The presence of AR in asthmatics increases the risk of asthma exacerbations, hospitalizations, and emergency room visits. ${ }^{11}$ Moreover, the greater the severity of AR, the worse the asthma control. ${ }^{12}$ Allergic rhinitis and asthma (ARA) are an important cause of disability, carrying a high social and economic impact on patients, families, and health care systems. ${ }^{4}$ For asthma in particular, patients with severe and uncontrolled disease account for the use of more health resources and a much larger share of health costs than patients with controlled disease. ${ }^{3}$

The Global Initiative for Asthma guidelines state that the goals of asthma therapy are to achieve overall control for extended periods in order to minimize the impact of the disease, decrease the medical costs related to asthma therapy and hospital services, and reduce the potential for adverse effects. ${ }^{5}$ When asthma is under control, there should be no more than occasional symptoms, and exacerbations should be rare. ${ }^{1}$ Nevertheless, many asthmatics have relatively low expectations of their medication clinical outcomes and accept a lower level of control than what could be achieved by optimizing therapy. ${ }^{13-15}$

Several standardized measures to assess the clinical control of asthma have been developed. One of the validated instruments is the Asthma Control Test (ACT) ${ }^{16}$ Methods to assess control of AR are also being introduced. ${ }^{5,17}$ Recently, the Control of Allergic Rhinitis and Asthma Test (CARAT) was developed and validated to simultaneously assess control of diseases of the upper and lower airways. ${ }^{18-20}$

The CARAT has been used in clinical practice but has not been studied in a community pharmacy setting. There are few studies that analyze the role of pharmacists for detecting level of ARA control. The existing studies conducted in pharmacies mainly assess the control level of asthma and, in general, poor asthma control. ${ }^{21-23}$ Identifying patients with poor ARA control may be the first step to helping patients obtain adequate treatment and to optimizing disease control.

This study assessed ARA control in patients with asthma, with AR, and with ARA at community pharmacies, using the CARAT tool for assessment.

\section{Methods}

\section{Study Design and Participants}

This was a cross-sectional study conducted at pharmacies in Covilhã, a county of 53,000 inhabitants in the interior central region of Portugal. All pharmacies in the county were contacted and invited to participate; 15 of the 18 pharmacies agreed to collaborate in the study.

Patients aged between 18 and 70 years with a refill prescription for AR and/or asthma-specific medication were included. Patients who were not able to understand or participate in the study were excluded (Figure 1). Exclusion criteria included refusal to participate in the study, illiteracy, presenting prescriptions for other people, and aged $<18$ or $>70$ years.

This study was approved by the ethics committee of the Faculty of Health Sciences of the University of Beira Interior. All participants signed a written informed consent form. Information in the questionnaires was kept anonymous.

\section{Data Collection}

Data were collected between December 2011 and May 2012, using an anonymous self-report questionnaire. Pharmacy personnel (i.e., pharmacists and pharmacy technicians) assisted 
Evaluation of Allergic Rhinitis and Asthma Control in a Portuguese Community Pharmacy Setting

TABLE 1 Subgroup Answers on CARAT Questionnaire ${ }^{a}$

\begin{tabular}{|c|c|c|c|c|c|c|c|c|c|c|c|c|}
\hline \multirow[b]{2}{*}{ Questions } & \multicolumn{3}{|c|}{ Never } & \multicolumn{3}{|c|}{$\begin{array}{l}\text { Up to } 2 \text { Days } \\
\text { Per Week }\end{array}$} & \multicolumn{3}{|c|}{$\begin{array}{c}\text { More Than } 2 \text { Days } \\
\text { Per Week }\end{array}$} & \multicolumn{3}{|c|}{$\begin{array}{c}\text { Almost Every Day } \\
\text { or Every Day }\end{array}$} \\
\hline & A & AR & $\mathrm{T}$ & A & AR & $\mathrm{T}$ & A & AR & $\mathrm{T}$ & A & AR & $\mathrm{T}$ \\
\hline 1. Blocked nose & 14 & 13 & 13 & 34 & 38 & 36 & 27 & 29 & 28 & 25 & 21 & 23 \\
\hline 2. Sneezing & 8 & 9 & 8 & 30 & 38 & 31 & 28 & 30 & 29 & 34 & 29 & 32 \\
\hline 3. Itchy nose & 21 & 24 & 22 & 30 & 38 & 31 & 23 & 26 & 25 & 26 & 18 & 22 \\
\hline 4. Runny nose & 23 & 14 & 18 & 32 & 40 & 36 & 21 & 23 & 22 & 25 & 23 & 24 \\
\hline 5. Dyspnea & 28 & 76 & 50 & 39 & 14 & 27 & 18 & 9 & 13 & 16 & 2 & 9 \\
\hline 6. Wheezing in the chest & 29 & 77 & 51 & 32 & 15 & 24 & 16 & 4 & 10 & 23 & 4 & 14 \\
\hline 7. Chest tightness upon physical exercise & 30 & 77 & 52 & 32 & 19 & 26 & 26 & 3 & 15 & 13 & 1 & 7 \\
\hline 8. Limitations in doing daily tasks & 19 & 52 & 34 & 35 & 38 & 36 & 23 & 7 & 15 & 23 & 4 & 14 \\
\hline \multirow[t]{2}{*}{ 9. Wake up during the night } & 18 & 40 & 28 & 30 & 31 & 30 & 29 & 20 & 25 & 23 & 9 & 17 \\
\hline & \multicolumn{3}{|c|}{ Not Taking Medication } & \multicolumn{3}{|c|}{ Never } & \multicolumn{3}{|c|}{ Less Than 7 Days } & \multicolumn{3}{|c|}{7 or More Days } \\
\hline 10. Medication use increase & 13 & 33 & 22 & 23 & 25 & 24 & 42 & 32 & 37 & 23 & 11 & 17 \\
\hline \multicolumn{13}{|c|}{$\begin{array}{l}\text { aAll answers are given as a percentage. Cohort numbers: asthma and rhinitis }(n=120) \text {; allergic rhinitis only }(n=104) \text {; total sample }(n=2 \\
\text { frequent response for each question. } \\
A=\text { asthma and rhinitis group; } A R=\text { allergic rhinitis only group; CARAT = Control of Allergic Rhinitis and Asthma Test; } T=\text { total sample. }\end{array}$} \\
\hline
\end{tabular}

in completing the questionnaire when necessary, for example, when the patient did not understand some of the terms used or had difficulty perceiving the scales. The level of asthma and allergic rhinitis control was assessed by the validated questionnaire CARAT and by a Visual Analogue Scale (VAS). ${ }^{19}$ Asthma control was also assessed by the ACT. ${ }^{24}$ Additional collected data included age, gender, smoking habits, and family history of allergic disease.

Participants were grouped according to the prescribed medication (for medication used in this study, see the Appendix). Those participants with an asthma-specific medication and an AR-specific medication were included in the "asthma and rhinitis" group, and those with an AR-specific medication but without an asthma medication were included in the "AR only" group. The ACT questionnaire was completed only by patients in the AR group.

CARAT has 10 questions that ask about symptomatology during the previous 4 weeks (Table 1). CARAT total score (CARAT-t) ranges from 0 to 30, with a score higher than 24 indicating good overall control. The questionnaire is further divided into 2 sections: the first section relates to allergic rhinitis (CARAT-r), with a score range of 0 to 12 and a value higher than 8 identifying controlled AR; the second section relates to asthma (CARAT-a), with a score range of 0 to 18 and a value of 16 or higher identifying controlled asthma. ${ }^{19,25}$

The VAS measures overall symptom severity, nasal symptoms, and bronchial symptoms, using a scale of 1 to 10 , where a score of 1 means no symptoms or untroublesome symptoms, and a score of 10 indicates the worst possible or extremely troublesome symptoms. Patients who responded with answers from 1 to 6 were considered to have "controlled" symptoms, and those who answered within the range of 6 to 10 were classified as "not controlled."

\section{Statistical Analysis}

Data analysis was performed using the SPSS software package, version 19.0 (SPSS Inc., Chicago, IL). Categorical variables were described by absolute (n) and relative (\%) frequencies, and the continuous variables were described with appropriate measures. When the association between categorical and continuous variables was dichotomous, the Mann-Whitney U-test or Student's t-test were used. In the case of variables with 3 or more categories, the Kruskal-Wallis test or analysis of variance were used, when appropriate. The chi-square test analyzed associations between categorical variables, and the association between scores of the different questionnaires was carried out using the Pearson's or Spearman's correlation coefficient.

Statistically significant differences between 2 variables were accepted when the probability of significance ( $P$ value) was $<0.05$.

\section{Results}

We invited 333 patients with asthma and/or AR to participate, and 224 were included and completed the questionnaires. Of the 82 patients who did not meet the inclusion criteria, 55 did not provide a prescription in their own name, and the remaining were younger or older than the target population. Of the 224 eligible patients, 120 had a prescription for a medication to treat asthma and therefore also filled in the ACT (Figure 1). Participants were aged between 18 and 70 years, with a median of 48.5 years. Of those with asthma and allergic rhinitis, the median age was 54.5 years, and the most frequent age group was $61-70$ years (32\%, Table 2 ). For the AR only group, the median age was 42.0 years. The gender distribution of the total sample showed a slight predominance of females (58\%). About $94 \%$ of the subjects lived in the county of Covilhã and were 


\section{TABLE 2 Participant Characteristics ${ }^{a}$}

\begin{tabular}{|c|c|c|c|}
\hline & $\begin{array}{c}\text { Total } \\
(\mathbf{n}=224)\end{array}$ & $\begin{array}{l}\text { Asthma and } \\
\text { Rhinitis } \\
(\mathrm{n}=120)\end{array}$ & $\begin{array}{l}\text { Allergic } \\
\text { Rhinitis Only } \\
(\mathrm{n}=104)\end{array}$ \\
\hline \multicolumn{4}{|l|}{ Gender } \\
\hline Male & $94 \quad(42.0)$ & $52 \quad(43.4)$ & $42 \quad(40.4)$ \\
\hline Female & $130 \quad(58.0)$ & $68 \quad(56.7)$ & $62 \quad(59.6)$ \\
\hline \multicolumn{4}{|l|}{ Age groups in years } \\
\hline $18-30$ & $\begin{array}{ll}46 & (20.5) \\
\end{array}$ & $17 \quad(14.2)$ & $29 \quad(27.9)$ \\
\hline $31-40$ & $37 \quad(16.5)$ & $18 \quad(15.0)$ & $19 \quad(18.3)$ \\
\hline $41-50$ & 35 (15.6) & $15(12.5)$ & $20 \quad(19.2)$ \\
\hline $51-60$ & $56 \quad(25.0)$ & $32 \quad(26.7)$ & $24 \quad(23.1)$ \\
\hline $61-70$ & $50 \quad(22.3)$ & $38 \quad(31.7)$ & $12 \quad(11.5)$ \\
\hline \multicolumn{4}{|l|}{ Years of education } \\
\hline Did not attend school & $8 \quad(3.6)$ & $(5.0)$ & (1.9) \\
\hline$<4$ & $21 \quad(9.4)$ & 19 (15.8) & $2 \quad(1.9)$ \\
\hline $4-9$ & $58 \quad(25.9)$ & $35 \quad(29.2)$ & $23 \quad(22.1)$ \\
\hline $9-12$ & $51 \quad(22.8)$ & $28 \quad(23.3)$ & $23 \quad(22.1)$ \\
\hline$>12$ & $86 \quad(38.4)$ & $32(26.7)$ & $54 \quad(51.9)$ \\
\hline \multicolumn{4}{|l|}{ Pharmacy type } \\
\hline Urban & $117 \quad(52.2)$ & $62 \quad(51.7)$ & $55 \quad(52.9)$ \\
\hline Rural & $107 \quad(47.8)$ & $58 \quad(48.3)$ & $49 \quad(47.1)$ \\
\hline \multicolumn{4}{|l|}{ Residence } \\
\hline Urban & $105 \quad(46.9)$ & $56 \quad(46.7)$ & $49 \quad(47.1)$ \\
\hline Rural & $106 \quad(47.3)$ & $60 \quad(50.0)$ & $46 \quad(44.2)$ \\
\hline Out of the county & $13 \quad(5.8)$ & $4 \quad(3.3)$ & $(8.7)$ \\
\hline \multicolumn{4}{|l|}{ Smoking habits } \\
\hline Smoker & $28 \quad(12.5)$ & $13(10.8)$ & $15 \quad(14.4)$ \\
\hline Nonsmoker & $155 \quad(69.2)$ & $80 \quad(66.7)$ & $75 \quad(72.1)$ \\
\hline Ex-smoker & $41 \quad(18.3)$ & $27 \quad(22.5)$ & $14 \quad(13.5)$ \\
\hline \multicolumn{4}{|l|}{ Environmental smoke } \\
\hline None & $165(73.7)$ & $85 \quad(70.8)$ & $80 \quad(76.9)$ \\
\hline At home & $37 \quad(16.5)$ & $26 \quad(21.7)$ & $11 \quad(10.6)$ \\
\hline At work & $15 \quad(6.7)$ & $7 \quad(5.8)$ & $(7.7)$ \\
\hline Both & $7 \quad(3.1)$ & $2 \quad(1.7)$ & $(4.8)$ \\
\hline Family history of asthma & $93 \quad(41.5)$ & $61 \quad(50.8)$ & $32(30.8)$ \\
\hline $\begin{array}{l}\text { Family history of } \\
\text { allergic rhinitis }\end{array}$ & $98 \quad(43.8)$ & $49 \quad(40.8)$ & $49 \quad(47.1)$ \\
\hline \multicolumn{4}{|c|}{$\begin{array}{l}\text { aParticipants in subgroups had a prescription for allergic rhinitis medication only } \\
(n=104) \text { or had a prescription for asthma and/or allergic rhinitis medication } \\
(n=120) \text {. All answers are given as } n(\%) \text {. }\end{array}$} \\
\hline
\end{tabular}

evenly distributed between urban and rural areas (105 and 106 inhabitants, respectively, Table 2).

\section{Asthma and Allergic Rhinitis Control}

Study results showed that the level of control was higher for males than for females, $18 \%$ versus $10 \%(P<0.05$, Table 3$)$. The average CARAT-t was 19 for males and 17 for females $(P=0.005$, data not shown). ARA control was higher for the younger age groups compared with the older age groups $(P<0.05$, Table 3$)$. For the age group 18-30, the median CARAT score was 21 points, and for the age group 61-70, the median was 15. The frequency of uncontrolled individuals, according to CARAT-a, is markedly higher than the controlled in all age groups. However, control decreased with increasing age $(P<0.001$, data not shown). In general, ARA control was greater with increased years of education $(P<0.05$, Table 3$)$. Regarding the CARAT-t, the median score was 20.5 for those who had studied more than 12 years, while for those who did not attend school the median score was 14.5. The control level was similar for those who had no family history of asthma when compared with those with at least 1 family member with asthma (14\% vs. 13\%, Table 3). However, the average CARAT-t score was significantly higher for those with no family history of asthma, 19 and 17 , respectively ( $P=0.015$, data not shown). The CARAT questionnaire answers are summarized in Table 1. For the questions related to AR symptoms, the most frequent answer was "up to 2 days per week" regarding asthma symptoms; the option "never" was the most frequent in the allergic rhinitis symptoms questions. In the asthma and rhinitis group, almost $16 \%$ of participants claimed to have shortness of breath "almost every day or every day." For the AR only group, 21\% had blocked nose "almost every day or every day."

The majority of individuals had uncontrolled disease (86.6\%, Table 4 and Figure 2A). The median scores were 19, 6, and 13 for CARAT-t, CARAT-r, and CARAT-a, respectively (data not shown). For participants who completed the ACT, only about $25 \%$ had controlled disease (Figure 2B). In contrast, most patients had a perception of good disease control, with $50.8 \%$ of the participants rating their asthma as "more or less controlled," $28.3 \%$ as "well controlled," and 10\% as "completely controlled." The median ACT score was 16 (mean = $16.6 \pm 4.3$ ). Only 7 participants (5.8\%) achieved complete control of asthma (score of 25 in ACT, Figure 2B).

VAS and CARAT had opposite scoring patterns: high score is good control for CARAT and bad for VAS. For all the VAS, the frequencies of uncontrolled were much higher compared with controlled (Table 4). For the total sample, the nasal symptoms presented a smaller level of no control (66.1\%, Table 4) than the bronchial symptoms (73.2\%, Table 4). Compared with CARAT, the VAS results reflect a slightly better control for both upper and lower airways (Table 4).

\section{Associations Between Control Measures}

The correlations coefficients between CARAT-t, ACT, and VAS are shown in Table 5. The values between CARAT and VAS are negative because good control on CARAT means poor control on VAS. The association with regard to ACT was made with CARAT-a because only these data are related to asthma control. There was a strong correlation between CARAT-a and ACT $(r=0.799)$. The correlations between CARAT- $r$ and nasal symptoms on VAS were lower $(r=-0.485)$.

\section{Discussion}

This study was the first conducted in a community pharmacy setting in Portugal that assessed the evaluation of both AR and 
Evaluation of Allergic Rhinitis and Asthma Control in a Portuguese Community Pharmacy Setting

TABLE 3 Asthma Control According to CARAT-t Score by Sociodemographic Features ${ }^{a}$

\begin{tabular}{|c|c|c|c|c|c|c|}
\hline & \multicolumn{2}{|c|}{ Total $(n=224)$} & \multicolumn{2}{|c|}{ Asthma and Rhinitis $(n=120)$} & \multicolumn{2}{|c|}{ Allergic Rhinitis Only $(n=104)$} \\
\hline & Controlled & Not Controlled & Controlled & Not Controlled & Controlled & Not Controlled \\
\hline \multicolumn{7}{|l|}{ Gender } \\
\hline Male & $17(18.1)^{\mathrm{b}}$ & $77 \quad(81.9)^{b}$ & $11 \quad(21.2)^{b}$ & $41 \quad(78.8)^{b}$ & $8 \quad(19.0)$ & $34 \quad(81.0)$ \\
\hline Female & $13(10.0)^{\mathrm{b}}$ & $117(90.0)^{\mathrm{b}}$ & $6 \quad(8.8)^{b}$ & $62 \quad(91.2)^{b}$ & $7 \quad(11.3)$ & $55 \quad(88.7)$ \\
\hline \multicolumn{7}{|l|}{ Age groups in years } \\
\hline $18-30$ & $9(19.6)^{b}$ & $37(80.4)^{b}$ & $3 \quad(17.6)$ & $14 \quad(82.4)$ & $5 \quad(17.2)$ & $24 \quad(82.8)$ \\
\hline $31-40$ & $5(13.5)^{b}$ & $32(86.5)^{\mathrm{b}}$ & $5 \quad(27.8)$ & $13 \quad(72.2)$ & $1 \quad(5.3)$ & $18 \quad(94.7)$ \\
\hline $41-50$ & $9(25.7)^{b}$ & $26(74.3)^{\mathrm{b}}$ & $2(13.3)$ & $13 \quad(86.7)$ & $6 \quad(30.0)$ & $14 \quad(70.0)$ \\
\hline $51-60$ & $4 \quad(7.1)^{\mathrm{b}}$ & $52(92.9)^{\mathrm{b}}$ & $1 \quad(3.1)$ & $31 \quad(96.9)$ & $(4.2)$ & $23 \quad(95.8)$ \\
\hline $61-70$ & $3 \quad(6.0)^{b}$ & $47 \quad(94.0)^{\mathrm{b}}$ & $6 \quad(15.8)$ & $32 \quad(84.2)$ & $2(16.7)$ & $10 \quad(83.3)$ \\
\hline \multicolumn{7}{|l|}{ Years of education } \\
\hline Did not attend school & $0 \quad(0.0)^{\mathrm{b}}$ & $8(100.0)^{b}$ & $\mathrm{l} \quad(16.7)^{\mathrm{b}}$ & $5(83.3)^{b}$ & $1 \quad(50.0)$ & $1 \quad(50.0)$ \\
\hline$<4$ & $1 \quad(4.8)^{b}$ & $20(95.2)^{b}$ & $2(10.5)^{b}$ & $17 \quad(89.5)^{\mathrm{b}}$ & $1 \quad(50.0)$ & $1 \quad(50.0)$ \\
\hline $4-9$ & $4 \quad(6.9)^{b}$ & $54 \quad(93.1)^{\mathrm{b}}$ & $3 \quad(8.6)^{b}$ & $32(91.4)^{b}$ & $1 \quad(4.3)$ & $22 \quad(95.7)$ \\
\hline $9-12$ & $7 \quad(13.7)^{\mathrm{b}}$ & $44 \quad(86.3)^{b}$ & $5 \quad(17.9)^{b}$ & $23(82.1)^{b}$ & $2 \quad(8.7)$ & $21 \quad(91.3)$ \\
\hline$>12$ & $18 \quad(20.9)^{\mathrm{b}}$ & $68 \quad(79.1)^{\mathrm{b}}$ & $6 \quad(18.8)^{b}$ & $26(81.3)^{b}$ & $10 \quad(18.5)$ & $44 \quad(81.5)$ \\
\hline \multicolumn{7}{|l|}{ Pharmacy type } \\
\hline Urban & $15 \quad(12.8)$ & $102 \quad(87.2)$ & $10 \quad(16.1)$ & $52 \quad(86.9)$ & $8 \quad(14.5)$ & $47 \quad(85.5)$ \\
\hline Rural & $15 \quad(14.0)$ & $92 \quad(86.0)$ & $7 \quad(12.1)$ & $51 \quad(87.9)$ & $7 \quad(14.3)$ & $42 \quad(86.7)$ \\
\hline \multicolumn{7}{|l|}{ Residence } \\
\hline Urban & $16 \quad(15.2)$ & $89 \quad(84.8)$ & $9 \quad(16.1)$ & $47 \quad(83.9)$ & $\begin{array}{ll}7 & (14.3) \\
\end{array}$ & $42 \quad(86.7)$ \\
\hline Rural & $11 \quad(10.4)$ & $95 \quad(89.6)$ & $7 \quad(11.7)$ & $53 \quad(88.3)$ & $6 \quad(13.0)$ & $40 \quad(87.0)$ \\
\hline Out of the county & $3(23.1)$ & $10 \quad(76.9)$ & $1 \quad(25.0)$ & $3(75.0)$ & $2 \quad(22.2)$ & $7 \quad(77.3)$ \\
\hline \multicolumn{7}{|l|}{ Smoking habits } \\
\hline Smoker & $4 \quad(14.3)$ & $24 \quad(85.7)$ & $2 \quad(15.4)$ & $11 \quad(84.6)$ & $\begin{array}{ll}5 & (33.3) \\
\end{array}$ & $10 \quad(66.7)$ \\
\hline Nonsmoker & $22 \quad(14.2)$ & $133 \quad(85.8)$ & $10 \quad(12.5)$ & $70 \quad(87.5)$ & $8 \quad(10.7)$ & $67 \quad(89.3)$ \\
\hline Ex-smoker & $4 \quad(9.8)$ & $37 \quad(90.2)$ & $5 \quad(18.5)$ & $22 \quad(81.5)$ & $2(14.3)$ & $12 \quad(85.7)$ \\
\hline \multicolumn{7}{|l|}{ Environmental smoke } \\
\hline None & $22(13.3)$ & $143(86.7)$ & $11 \quad(12.9)$ & $74 \quad(87.1)$ & $10 \quad(12.5)$ & $70 \quad(87.5)$ \\
\hline At home & $4 \quad(10.8)$ & $33 \quad(89.2)$ & $4 \quad(15.4)$ & $22 \quad(84.6)$ & $2(18.2)$ & $9 \quad(81.8)$ \\
\hline At work & $3(20.0)$ & $12(80.0)$ & $1 \quad(14.3)$ & $6 \quad(85.7)$ & $1 \quad(12.5)$ & $7 \quad(87.5)$ \\
\hline Both & $1 \quad(14.3)$ & $6 \quad(85.7)$ & $1 \quad(50.0)$ & $1 \quad(50.0)$ & $2(40.0)$ & $3(60.0)$ \\
\hline Family history of asthma & $12(12.9)^{\mathrm{b}}$ & $81 \quad(87.1)^{b}$ & $4 \quad(6.6)$ & $57 \quad(93.4)$ & $7 \quad(21.9)$ & $25(78.1)$ \\
\hline Family history of allergic rhinitis & $14 \quad(14.3)$ & $84 \quad(85.7)$ & $6 \quad(12.2)$ & $43 \quad(87.8)$ & $7 \quad(14.3)$ & $42 \quad(85.7)$ \\
\hline
\end{tabular}

asthma control. ARA control is markedly low as measured by these study methods. In patients who experienced AR only, merely $16 \%$ of the sample reported symptom control, and in the participants treated for asthma and rhinitis, 14\% reported disease control.

ARA control, and specifically asthma control, was lower in older participants. This finding is in agreement with previously reported results, where lower asthma control is associated with increasing age. 12,22,27 There are several possible explanations, including concomitant chronic obstructive pulmonary disease (COPD), side effects of other medications, and complicated medication regimens that may inhibit or interfere with adherence with all therapy regimens. ${ }^{22}$
According to the ACT, $75 \%$ of the patients had poorly controlled asthma. This value was higher than that obtained in other Portuguese studies that used ACT. A different project, also carried out in a pharmacy environment, had $61.2 \%$ of the volunteers with an ACT score $<20,{ }^{22}$ and a study that assessed patients treated at allergy departments in hospitals had 23.3\% of the volunteers with an ACT score $<20 .{ }^{28}$ These differences may be related not only to regional and sociodemographic factors, but also to the health care setting, the hospital, or the community pharmacy.

The analysis of the question "how would you rate your asthma control during the past 4 weeks" showed that the majority of the participants had a poor perception of their level 
Evaluation of Allergic Rhinitis and Asthma Control in a Portuguese Community Pharmacy Setting

TABLE 4 Participants with Uncontrolled Disease According to CARAT Scores and VAS ${ }^{a}$

\begin{tabular}{|c|c|c|c|c|c|c|}
\hline \multirow[b]{2}{*}{ CARAT- $\mathrm{t}$} & \multicolumn{2}{|c|}{ Total $(n=224)$} & \multicolumn{2}{|c|}{ Asthma and Rhinitis $(\mathrm{n}=120)$} & \multicolumn{2}{|c|}{ Allergic Rhinitis Only $(n=104)$} \\
\hline & 194 & $(86.6)$ & 108 & $(90.0)$ & 86 & $(82.7)$ \\
\hline CARAT-r & 189 & $(84.4)$ & 100 & $(83.3)$ & 89 & $(85.6)$ \\
\hline CARAT-a & 161 & $(71.9)$ & 103 & $(85.8)$ & 58 & $(55.8)$ \\
\hline VAS all symptoms & 161 & $(71.9)$ & 75 & $(62.5)$ & 86 & $(82.7)$ \\
\hline VAS nasal symptoms & 148 & $(66.1)$ & 81 & $(67.5)$ & 78 & $(65.0)$ \\
\hline VAS bronchial symptoms & 164 & $(73.2)$ & 67 & $(64.4)$ & 86 & $(82.7)$ \\
\hline
\end{tabular}

of control, with only $11 \%$ of the asthmatics reporting their asthma as not controlled or poorly controlled. One possible explanation for the difference between patients' perception of control is that individuals who have poorly controlled disease adapt to frequently feeling poorly. ${ }^{29}$ The sharp contrast between perception of control and the status of control suggests that filling out a CARAT while at their local pharmacy may be an opportunity for patients to increase their awareness of poor disease control. Using a simple self-assessment questionnaire, such as the CARAT, pharmacists can help identify patients with uncontrolled ARA disease, which is an important first step to change patients' knowledge about their disease, with an ultimate goal of improving ARA outcomes.

The results of this study, showing overall poor asthma control in a community population, are similar to those obtained in 3 other studies that recruited patients from a similar setting. One study conducted at 348 pharmacies in 9 French cities showed that patients with ARA have a low degree of control, as measured by a questionnaire, while the study volunteers reported that their asthma was well controlled or completely controlled. ${ }^{23}$ Another study, conducted via patient questionnaire at 54 pharmacies in Flanders, showed a high percentage of insufficiently controlled asthmatic patients, as assessed by patient responses and peak expiratory flow rate. ${ }^{21}$ A study carried out in Portugal evaluated the degree of asthma control with a self-reported diagnosis and concomitant asthma therapy using ACT. The authors found a high degree of uncontrolled asthma, especially in older patients and, in general, a blunted perception of disease control. ${ }^{22}$

In the pharmacy setting, following the assessment of ARA control, some additional interventions may be proposed. Adherence to treatment is a key factor, ${ }^{30}$ with increased compliance associated with better disease control. ${ }^{27}$ Asthma education and pharmaceutical interventions can improve its control..$^{14,15}$ The potential benefits of a pharmacist's contribution to asthma management have been previously reported. ${ }^{31-33}$ Briefly, in Portugal, the health system is public and universal, but the pharmacies are private with guaranteed universal access. As such, the community pharmacy is in an optimal place to provide information about medication benefits, including frequency of administration, methods to reduce side effects, and correct use of inhaler devices. ${ }^{22}$ In the majority of Portuguese pharmacies, a software is used that allows pharmacists to create a file for each user and keep records of all prescribed medication, over-the-counter (OTC) drugs, and historical results of measurements conducted in the pharmacy. This same system can also be used to record the CARAT results by date. The score of the questionnaire can help the pharmacist to justify an OTC indication or the need for a medical consultation. Furthermore, in order to contribute to the dissemination of CARAT, a website and a smartphone application, mCARAT, have been developed. This application allows patients to fill out the questionnaire, sets alarms for tasks such as taking medications, and includes several features for recording symptoms, exacerbations, and scheduled or unscheduled medical visits. ${ }^{34}$ The results can be shared via e-mail with other users and also with the physician.

It is important to recognize possible causes for the low degree of observed disease control. In addition to poor perception of asthma control, adults with poorly controlled disease may not be aware of the availability of effective anti-inflammatory medication. Poor disease control may also be associated with low continuity of care related to a poor doctor-patient relationship, negative attitudes and concerns about the use of medication, overreliance on quick-relief bronchodilators, and little understanding of the disease, as there are more uncontrolled patients that are not aware of the causes underlying their pathology. ${ }^{29}$

Future studies should address reasons contributing to poor ARA control and evaluate the cost-effectiveness of community pharmacy-based assessment of ARA.

\section{Limitations}

This study has several limitations that could affect the generalizability of the results. First, the number of participants in the study is insufficient to extrapolate the data to a national context. Second, since this study relied only on the patients who presented a prescription for an allergy and/or asthma 


\section{FIGURE 2 Score Distribution}

A. CARAT-t $(n=224)$

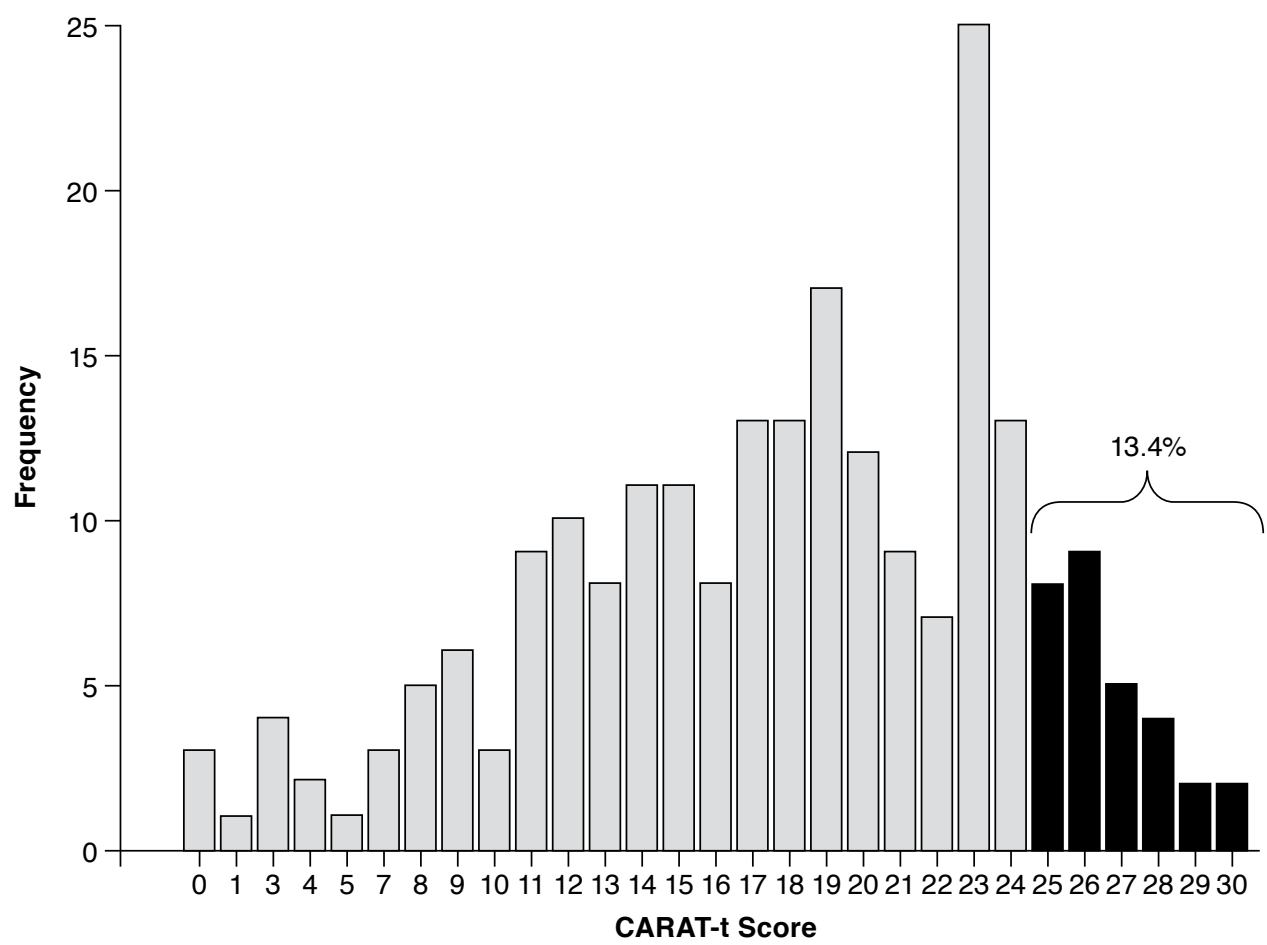

B. ACT for AR Subgroup $(n=120)$

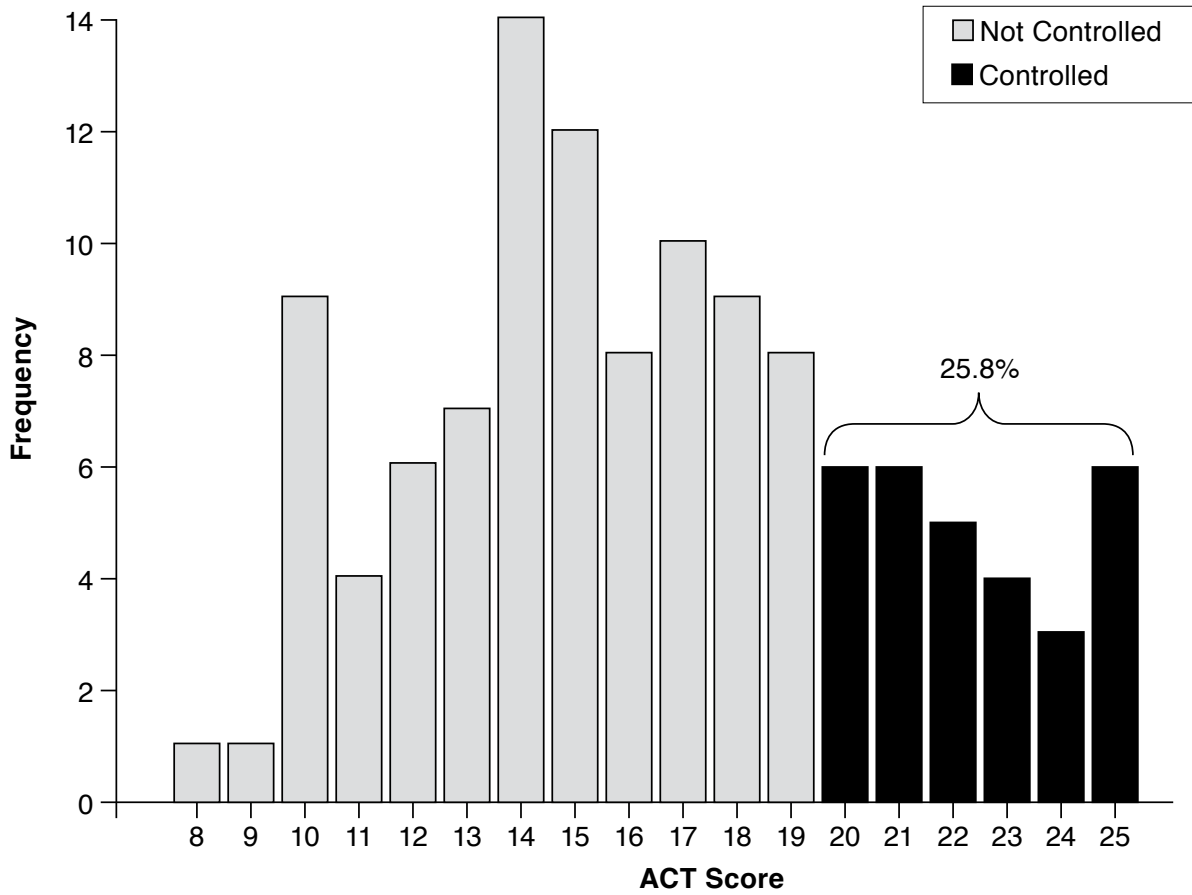

$A C T=$ Asthma Control Test $; A R=$ allergic rhinitis only group; $C A R A T=$ Control of Allergic Rhinitis and Asthma Test; CARAT-t=CARAT total score. 


\begin{tabular}{|c|c|c|c|c|c|}
\hline & & ACT & $\begin{array}{c}\text { VAS All } \\
\text { Symptoms }\end{array}$ & $\begin{array}{l}\text { VAS Nasal } \\
\text { Symptoms }\end{array}$ & $\begin{array}{c}\text { VAS } \\
\text { Bronchial } \\
\text { Symptoms }\end{array}$ \\
\hline \multirow{3}{*}{ Total } & CARAT- $\mathrm{t}$ & & \multirow[t]{3}{*}{-0.609} & \multirow{3}{*}{-0.485} & \\
\hline & CARAT-r & & & & \\
\hline & CARAT-a & & & & -0.651 \\
\hline \multirow{3}{*}{$\begin{array}{l}\text { Asthma and } \\
\text { rhinitis }\end{array}$} & CARAT- $t$ & \multirow[t]{2}{*}{0.764} & \multirow[t]{3}{*}{-0.567} & \multirow{3}{*}{-0.481} & \\
\hline & CARAT-r & & & & \\
\hline & CARAT-a & 0.799 & & & -0.672 \\
\hline \multirow{2}{*}{$\begin{array}{l}\text { Allergic } \\
\text { rhinitis only }\end{array}$} & CARAT-t & & \multirow[t]{2}{*}{-0.578} & \multirow[b]{2}{*}{-0.474} & \\
\hline & CARAT-r & & & & \\
\hline \multicolumn{6}{|c|}{$\begin{array}{l}\text { aCorrelations between CARAT and VAS are negative because better control in } \\
\text { CARAT means worse control in VAS (all } P<0.001) \text {. } \\
\text { ACT =Asthma Control Test; CARAT } \text { Control of Allergic Rhinitis and Asthma Test; } \\
\text { CARAT- } a=C A R A T \text { score for asthma; CARAT-r=CARAT score for allergic rhinitis } \\
\text { factor; CARAT- } t=\text { CARAT total score; VAS =Visual Analogue Scale. }\end{array}$} \\
\hline
\end{tabular}

medication and self-reported the pathology, we could not confirm that AR patients were not in fact ARA patients. Patients with AR using OTC medication only were not included, so AR may be underreported for prevalence, and control may be better than the study shows. Third, even though this study encompassed less than 12 months, AR is a seasonal disorder, and the occurrence of AR could affect the number of patients seeking treatment for it. Our results may also have included some patients with chronic obstructive pulmonary disease (COPD); however, considering that COPD is highly associated with smoking, the results observed were similar for smokers and nonsmokers (Table 3). Considering gender, men may have answered questions differently than women, possibly downplaying the effects of their disease. In addition, CARAT has not yet been validated in the AR only population, although some projects testing the CARAT with patients with AR only or asthma only are being carried out. Moreover, some patients may attribute fatigue to causes other than ARA, which may have affected their responses and, thus, some of the results.

\section{Conclusions}

This study demonstrated that asthma and AR control are far from optimal as measured by the CARAT tool in a community pharmacy setting. This study also showed that most patients have a poor perception of their disease control. Even with the identified limitations, the results show that patients who suffer from ARA may be identified by community pharmacies and offered assistance for improved disease control. Assessing ARA control at community pharmacies using simple self-assessment questionnaires, such as CARAT, may be a first step to change patient behaviors and to target educational initiatives aimed at improving ARA outcomes.

\section{Authors}

OLGA LOURENÇO, PhD, is Assistant Professor, and SOFIA CALADO, MS, is Community Pharmacist, CICS-UBI Health Sciences Research Centre, Universidade da Beira Interior, Covilhã, Castelo Branco, Portugal. ANA SÁ-SOUSA, MSc, is Researcher, CINTESIS-Center for Research in Health Technologies and Information Systems, Centro de Investigação Médica, Porto Portugal, and JOÃO FONSECA, PhD, is Assistant Professor, Health Information and Decision Sciences Department (CIM-FMUP), Faculdade de Medicina da Universidade do Porto, Porto, Portugal.

AUTHOR CORRESPONDENCE: Olga Lourenço, PhD, CICS-UBI Health Sciences Research Centre, University of Beira Interior, Av. Infante D. Henrique, Covilhã, Castelo Branco 6200-506, Portugal. Tel.: 351.275.329.009; Fax: 351.275.329.099; E-mail: olga@fcsaude.ubi.pt.

\section{DISCLOSURES}

Fonseca has been a consultant and speaker for Novartis. The authors report no other potential conflicts of interest or financial disclosures.

Concept and design for this study were contributed primarily by Lourenço, with help from Calado and Fonseca. Data were collected by Calado then interpreted by Calado and Sá-Sousa. The manuscript was written primarily by Calado, assisted by Lourenço, who also did revision along with Fonseca and Sá-Sousa.

\section{REFERENCES}

1. Global Initiative for Asthma. GINA report, global strategy for asthma management and prevention. December 2012. Available at: http://www.ginasthma.org/documents/4. Accessed March 10, 2014.

2. World Health Organization. Global surveillance, prevention and control of chronic respiratory diseases: a comprehensive approach. 2007. Available at: http://www.who.int/gard/publications/GARD\%20Book\%202007. pdf?ua=1. Accessed March 12, 2014

3. Sullivan SD. Asthma in the United States: recent trends and current status. J Manag Care Pharm. 2003;9(Suppl 5):3-7. Available at: http://www. amcp.org/WorkArea/DownloadAsset.aspx?id=14118.

4. Bousquet J, van Cauwenberge P, Khaltaev N, and the Aria Workshop Group. Allergic rhinitis and its impact on asthma. J Allergy Clin Immunol. 2001;108(Suppl 5):S147-334.

5. Bousquet J, Khaltaev N, Cruz AA, et al. Allergic rhinitis and its impact on asthma (ARIA) 2008 update (in collaboration with the World Health Organization, GA(2)LEN and AllerGen). Allergy. 2008;63(Suppl 86):8-160.

6. Bauchau V, Durham SR. Prevalence and rate of diagnosis of allergic rhinitis in Europe. Eur Respir J. 2004;24(5):758-64.

7. Morais-Almeida M, Loureiro C, Todo-Bom A, et al. Avaliação da prevalência e caracterização da rinite em utentes dos cuidados de saúde primários de Portugal Continental-Estudo ARPA. Rev Port Imunoalergol. 2005;13(1):69-80.

8. Bousquet J, van Cauwenberge P, Khaltaev N. ARIA in the pharmacy: management of allergic rhinitis symptoms in the pharmacy. Allergic rhinitis and its impact on asthma. Allergy. 2004;59(4):373-87.

9. Schatz M. A survey of the burden of allergic rhinitis in the USA. Allergy. 2007;62(Suppl 85):9-16.

10. Bousquet J, Vignola AM, Demoly P. Links between rhinitis and asthma. Allergy. 2003;58(8):691-706. 
11. Bousquet J, Jacot W, Vignola AM, Bachert C, Van Cauwenberge P. Allergic rhinitis: a disease remodeling the upper airways? J Allergy Clin Immunol. 2004;113(1):43-49.

12. Clatworthy J, Price D, Ryan D, Haughney J, Horne R. The value of selfreport assessment of adherence, rhinitis and smoking in relation to asthma control. Prim Care Respir J. 2009;18(4):300-5.

13. Bateman ED, Bousquet J, Keech ML, Busse WW, Clark TJ, Pedersen SE. The correlation between asthma control and health status: the GOAL study. Eur Respir J. 2007;29(1):56-62.

14. International consensus report on diagnosis and management of rhinitis. Allergy. 1994:49(Suppl 19):1-34.

15. Green RJ, Davis G. Burden of allergic rhinitis. Curr Allergy Clin Immunol. 2005;18(4):176-78.

16. Thomas M, Kay S, Pike J, et al. The asthma control test (ACT) as a predictor of GINA guideline-defined asthma control: analysis of a multinational cross-sectional survey. Prim Care Respir J. 2009;18(1):41-49.

17. Demoly P, Jankowski R, Chassany O, Bessah Y, Allaert FA. Validation of a self-questionnaire for assessing the control of allergic rhinitis. Clin Exp Allergy. 2011;41(6):860-68.

18. Nogueira-Silva L, Martins SV, Cruz-Correia R, et al. Control of allergic rhinitis and asthma test: a formal approach to the development of a measuring tool. Respir Res. 2009;10:52.

19. Fonseca JA, Nogueira-Silva L, Morais-Almeida M, et al. Validation of a questionnaire (CARAT10) to assess rhinitis and asthma in patients with asthma. Allergy. 2010;65(8):1042-48.

20. Fonseca JA, Nogueira-Silva L, Morais-Almeida M, et al. Control of allergic rhinitis and asthma test (CARAT) can be used to assess individual patients over time. Clin Transl Allergy. 2012;2(1):16.

21. Mehuys E, Van Bortel L, Annemans L, et al. Medication use and disease control of asthmatic patients in Flanders: a cross-sectional community pharmacy study. Respir Med. 2006;100(8):1407-14.

22. Mendes Z, Madeira A, Costa S, et al. Avaliação do controlo da asma através do Asthma Control Test TM aplicado em farmácias portuguesas. Rev Port Imunoalergol. 2010;18(4):313-30.
23. Laforest L, Van Ganse E, Devouassoux G, et al. Quality of asthma care: results from a community pharmacy based survey. Allergy. 2005;60(12):1505-10.

24. Nathan RA, Sorkness CA, Kosinski M, et al. Development of the asthma control test: a survey for assessing asthma control. J Allergy Clin Immunol. 2004;113(1):59-65.

25. CARAT. Teste de Controlo da Asma e Rinite Alérgica. 2014. Available at: http://www.caratnetwork.org/index.php?option=com_fastcarat\&lang=pt. Accessed March 11, 2014.

26. Bousquet PJ, Combescure C, Neukirch F, et al. Visual analog scales can assess the severity of rhinitis graded according to ARIA guidelines. Allergy. 2007;62(4):367-72.

27. Demoly P, Paggiaro P, Plaza V, et al. Prevalence of asthma control among adults in France, Germany, Italy, Spain and the UK. Eur Respir Rev. 2009;18(112):105-12

28. Ferreira MB, Alves RR, Santos AS, et al. Controlo da asma em consulta de imunoalergologia. Rev Port Imunoalergol. 2008;16(1):29-56.

29. Soriano JB, Rabe KF, Vermeire PA. Predictors of poor asthma control in European adults. J Asthma. 2003;40(7):803-13.

30. Laforest L, Van Ganse E, Devouassoux G, et al. Influence of patients' characteristics and disease management on asthma control. J Allergy Clin Immunol. 2006;117(6):1404-10.

31. Barbanel D, Eldridge S, Griffiths C. Can a self-management programme delivered by a community pharmacist improve asthma control? A randomised trial. Thorax. 2003;58(10):851-54.

32. Mehuys E, Van Bortel L, De Bolle L, et al. Effectiveness of pharmacist intervention for asthma control improvement. Eur Respir J. 2008;31(4):790-99.

33. Emmerton L, Shaw J, Kheir N. Asthma management by New Zealand pharmacists: a pharmaceutical care demonstration project. J Clin Pharm Ther. 2003;28(5):395-402.

34. Azevedo P, Correia de Sousa J, Bousquet J, et al. Control of allergic rhinitis and asthma test (CARAT): dissemination and applications in primary care. Prim Care Respir J. 2013;22(1):112-16. 


\section{APPENDIX List of International Common}

Denominations of the Selected

Medications Used in This Study

Beta-adrenergic Agonists

Quick action

- Salbutamol

- Terbutaline

Long action

- Salmeterol

- Formoterol

Cholinergic Antagonists

- Ipratropium bromide

Glucocorticoids

- Beclomethasone

- Budesonide

- Fluticasone

- Mometasone

- Betamethasone

Leukotriene Antagonists

- Montelukast

- Zafirlukast

Xanthines

- Aminophylline

- Theophylline

Cromones

- Cromoglycic acid

Antihistamines-Nonsedatives

- Loratadine

- Desloratadine

- Ebastine

- Fexofenadine

- Mizolastine

- Rupatadine

- Cetirizine

- Levocetirizine

- Ketotifen 